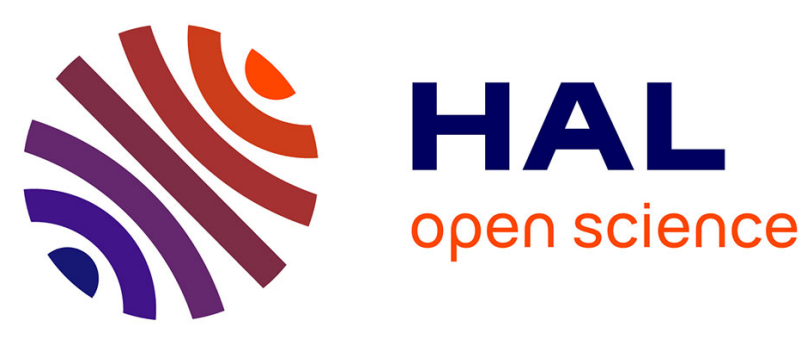

\title{
Chirality in Dynamic Supramolecular Nanotubes Induced by a Chiral Solvent
}

Benjamin Isare, Mathieu Linares, Loussiné Zargarian, Serge Fermandjian,

Motofumi Miura, Shigeyasu Motohashi, Nicolas Vanthuyne, Roberto

Lazzaroni, Laurent Bouteiller

\section{To cite this version:}

Benjamin Isare, Mathieu Linares, Loussiné Zargarian, Serge Fermandjian, Motofumi Miura, et al.. Chirality in Dynamic Supramolecular Nanotubes Induced by a Chiral Solvent. Chemistry - A European Journal, 2010, 16 (1), pp.173-177. 10.1002/chem.200902399 . hal-01696713

\section{HAL Id: hal-01696713 https://hal.science/hal-01696713}

Submitted on 26 Aug 2020

HAL is a multi-disciplinary open access archive for the deposit and dissemination of scientific research documents, whether they are published or not. The documents may come from teaching and research institutions in France or abroad, or from public or private research centers.
L'archive ouverte pluridisciplinaire HAL, est destinée au dépôt et à la diffusion de documents scientifiques de niveau recherche, publiés ou non, émanant des établissements d'enseignement et de recherche français ou étrangers, des laboratoires publics ou privés. 


\title{
Chirality in Dynamic Supramolecular Nano-tubes Induced by a Chiral Solvent
}

\author{
Benjamin Isare, ${ }^{[a, b]}$ Mathieu Linares, ${ }^{[c, d]}$ Loussiné Zargarian, ${ }^{[\mathrm{e}]}$ Serge Fermandjian, ${ }^{[\mathrm{e}]}$ Motofumi \\ Miura, ${ }^{[\mathrm{f}]}$ Shigeyasu Motohashi, ${ }^{[\mathrm{f}]}$ Nicolas Vanthuyne, ${ }^{[\mathrm{g}]}$ Roberto Lazzaroni ${ }^{[\mathrm{c}]}$ and Laurent \\ Bouteiller*[a,b]
}

\begin{abstract}
Amplification of chirality has been reported in polymeric systems. It has also been shown that related effects can occur in polymer-like dynamic supramolecular aggregates, if a subtle balance between noncovalent interactions allows the coupling between a chiral information and a cooperative aggregation process. In this context, we report a strong majority-
\end{abstract}

rules effect in the formation of chiral dynamic nano-tubes from chiral bisurea monomers. Furthermore, the same helical nano-tubes can be obtained from racemic monomers in a chiral solvent. Competition experiments reveal the relative strength of the helical bias induced by the chiral monomer or by the chiral solvent. The nano-tube handedness is imposed by the monomer chirality, whatever the solvent chirality. However, the chirality of the solvent has a significant effect on the degree of chiral induction.

Keywords: chirality $\bullet$ chiral
solvent $\bullet$ nano-tubes $\bullet$
supramolecular chemistry $\bullet$ self-
assembly

[a] Dr. B. Isare, Dr. L. Bouteiller

UPMC Univ Paris 06, UMR 7610, Chimie des Polymères, F-75005, Paris, France

Fax: (+33) 144277089

E-mail: laurent.bouteiller@upmc.fr

Homepage: http://www.lcp.upmc.fr/

[b] Dr. B. Isare, Dr. L. Bouteiller

CNRS, UMR 7610, Chimie des Polymères,

F-75005, Paris, France

[c] Dr. M. Linares, Dr. R. Lazzaroni

Service de Chimie des Matériaux Nouveaux, Université de Mons /Materia Nova, Place du Parc, 20, B-7000 Mons, Belgium

[d] Dr. M. Linares

Current address: Department of Physics, Chemistry and Biology, Linköping University, S-58183 Linköping, Sweden

[e] Dr. L. Zargarian, Dr. S. Fermandjian

LBPA - UMR 8113, Ecole Nationale Supérieure de Cachan, Bâtiment de l'Institut d'Alembert (IDA), 61 avenue du Président Wilson, 94235 Cachan Cedex, France

[f] M. Miura, Prof. S. Motohashi

College of Pharmacy, Nihon university 7-1, Narashinodai 7-chome Funabashi-shi, Chiba 274-8555, Japan

[g] Dr. N. Vanthuyne

UMR 6180 - Université Paul Cézanne, Avenue Escadrille Normandie Niémen, 13397 Marseille cedex 20, France

Supporting information for this article is available on the WWW under http://www.chemeurj.org/ or from the author.
The control of chirality amplification is a prominent objective, because understanding how a slight enantiomeric excess in a racemate can be amplified, may help unravel the mystery of the origin of chirality in biological systems. Amplification of chirality is also important for chemistry and materials science, in applications such as enantioselective catalysis and chiral separation or sensing. ${ }^{[1]}$ The amplification of chirality was first studied in polymeric systems and is now a well known phenomenon. ${ }^{[2]}$ More recently, it has been shown that related effects can also occur in polymer-like dynamic supramolecular aggregates, ${ }^{[3]}$ if a subtle balance between noncovalent interactions allows the coupling between a chiral information and a cooperative aggregation process. So far, most studies have dealt with non-linear effects occurring when a chiral monomer is mixed with a non-chiral monomer (sergeants-andsoldiers principle) or with its racemate (majority-rules principle).$^{[3]}$ In contrast, only few studies concern the effect of chiral additives, ${ }^{[4]}$ and even fewer report on the use of chiral solvents. ${ }^{[5-7]}$ However, from a practical point of view, the introduction of a chiral information in a dynamic supramolecular aggregate, via a simple chiral solvent instead of an elaborate chiral monomer, is certainly very attractive.

We have recently shown that racemic bis-ureas EHUT-rac selfassemble in non polar solvents to form extremely long nano-tubes, via a strongly cooperative process. ${ }^{[8]}$ These nano-tubes are in dynamic exchange with the monomer and with simple hydrogen bonded filaments. ${ }^{[8 \mathrm{a}]}$ Moreover they can form only if the solvent molecules are small enough to be accommodated within the tubes, 
thereby contributing to their stabilization. ${ }^{[8 b, e]}$ We therefore considered that this host-guest system was well suited to study the possibility of chirality transfer from the solvent to the supramolecular nano-tube. Herein, we report the formation of chiral dynamic nano-tubes (i) from chiral monomers, ${ }^{[6 a, 9]}$ or (ii) from racemic monomers in a chiral solvent, and (iii) the competition between the two processes.

\section{Results and Discussion}

Enantio-enriched monomers EHUT-SS and EHUT-RR were synthesized from toluene diisocyanate and the corresponding optically pure ${ }^{[10]}$ 2-ethylhexylamines. The optical purity of the monomers was characterized by chiral HPLC: their enantiomeric excess is $78 \%$ and $70 \%$ respectively (see Supporting Information). The reference compound EHUT-rac was obtained by reacting toluene diisocyanate with racemic 2-ethylhexylamine, and therefore contains the four isomers EHUT-SS, -RR, -RS and -SR in equimolar amounts (Scheme 1). The first step is to probe the supramolecular structure formed by an enantiopure monomer in comparison to the racemic mixture, because in some cases, chirality has been shown to strongly affect the assembly pattern. ${ }^{[3,11]}$ Figures S1 and S2 show that the SANS scattering curves and the FTIR spectra of EHUT-SS and EHUT-rac are identical, proving that the enantio-enriched monomer forms the same supramolecular architecture as the racemic mixture. Moreover, the high cooperativity of the transition between the nano-tubes and the filaments affords a sensitive measure of the relative stability of the two structures. ${ }^{[8]}$ This transition occurs at the same temperature for EHUT-SS and EHUT-rac (Figure S3), showing that the tube and filament structures are not significantly affected by the chirality of the monomer.
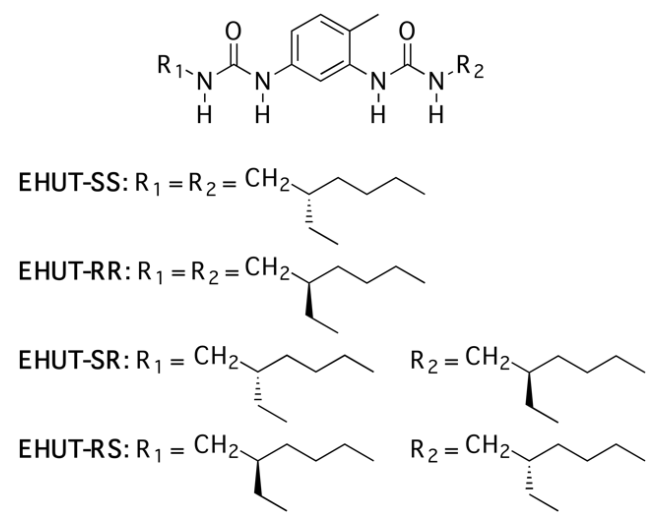

Scheme 1. Structure of bis-urea monomers.

CD spectroscopy was then used to investigate further the effect of the chiral side chains. No CD signal is observed for EHUT-SS in ethanol (data not shown), probably because no supramolecular structure is formed in this strongly interacting solvent, and the chiral centers are too far from the urea and aromatic chromophores. However, in cyclohexane at room temperature, a strong bisignated Cotton effect is observed with a negative and positive maxima at 236 and $224 \mathrm{~nm}$, respectively (Figure 1). A weak positive band also appears at $290 \mathrm{~nm}$. The comparison of this CD signal to the UVvisible absorption spectrum (Figure S4) suggests that the bisignated Cotton effect may result from an exciton coupling within the selfassembled nano-tube. In any case, the opposite CD signal obtained with the mirror image isomer EHUT-RR, and the disappearance of the $\mathrm{CD}$ signal at temperatures above the tube-filament transition $\left(51^{\circ} \mathrm{C}\right)$ are clear evidence that there is a transfer of chirality from the alkyl side chains of the monomer to the urea and aromatic chromophores within the self-assembled nano-tubes.

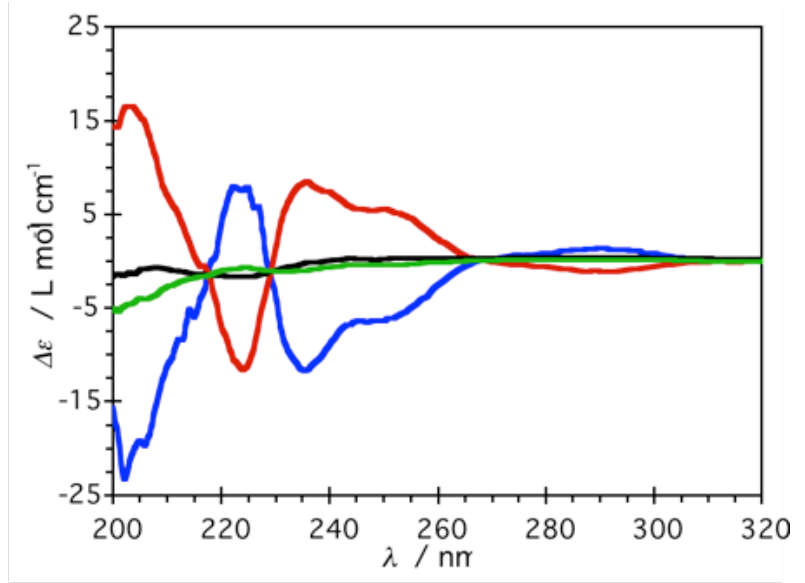

Figure 1. CD spectra of $1 \mathrm{mM}$ solutions in cyclohexane of: (a) EHUT-SS at $20^{\circ} \mathrm{C}$ (blue); (b) EHUT-RR at $20^{\circ} \mathrm{C}$ (red); (c) EHUT-SS at $60^{\circ} \mathrm{C}$ (green); (d) EHUT-rac at $20^{\circ} \mathrm{C}$ (black).

Mixing enantiomers is a simple method to obtain structural information on a self-assembled system. ${ }^{[3 a]}$ Therefore, stock solutions of EHUT-SS or EHUT-RR in cyclohexane were combined in different proportions and stirred at room temperature. Figure 2 shows the result of the $\mathrm{CD}$ measurements at equilibrium. ${ }^{[12]}$ The highly non-linear variation of the ellipticity is remarkable and shows that an enantiomeric excess of only $10 \%$ is sufficient to impose the chiral twist of the majority enantiomer. It also shows that the nano-tubes are indeed in dynamic exchange at room temperature, because this chiral amplification can only occur if the assemblies of the pure enantiomers reorganize after mixing. Moreover, this strong majority-rules effect is also observed if solutions of EHUT-SS and EHUT-rac are combined in different proportions (Figure 2). This means that the dilution by the other isomers (EHUT-SR and EHUT-RS) does not destroy the cooperativity of the process. Van Gestel et al. have recently reported a theoretical model which quantitatively describes chiral amplification effects in onedimensional self-assemblies. ${ }^{[13]}$ They showed that the two relevant parameters for such a system are the energetic penalty for a helix reversal $\left(\varepsilon_{\text {reversal }}\right)$ and the energetic penalty for the presence of a "wrong" enantiomer in an assembly of given helicity ( $\left.\varepsilon_{\text {mismatch }}\right)$. Following the fitting procedure of van Gestel et al., ${ }^{[13 c, d]}$ it is possible to obtain an excellent agreement with our experimental data (Figure 2) if values of the parameters are $\varepsilon_{\text {reversal }} \geq 17 \mathrm{~kJ} / \mathrm{mol}(=7$ $\left.\mathrm{k}_{\mathrm{B}} \mathrm{T}\right)$ and $\varepsilon_{\text {mismatch }} \leq 0.1 \mathrm{~kJ} / \mathrm{mol}\left(=0.05 \mathrm{k}_{\mathrm{B}} \mathrm{T}\right)$. The very low value for the mismatch penalty is not really surprising and reflects the small energetic destabilization of a $(R)$-ethylhexyl group within a predominantly $(S)$-ethylhexyl domain. It must be noted that the huge length of the tubes ${ }^{[8 \mathrm{~d}]}$ means that the overall mismatch energy for a given tube can still be significant. Moreover, the large value for a helix reversal penalty is very informative, because it implies that helix reversals are not likely to occur along a nano-tube. This in turn means that in racemates, the bisureas tend to self-assemble into a mixture of right-handed or left-handed nano-tubes (in adequate proportions), rather than in a kind of multiblock copolymer. Furthermore, the unfavorable interaction between right-handed and left-handed nano-tubes indicates a major influence of the chiral side 
chains on either the hydrogen bonding pattern or the steric environment of the nano-tubes. This last conclusion contradicts the previously reported molecular model for the nano-tube, where no twist was visible. ${ }^{[8 c]}$ However, the absence of twist was a consequence of the molecular simulation procedure adopted: periodic boundary conditions were imposed to avoid end effects due to the absence of hydrogen bonding. ${ }^{[14]}$ In the present work, molecular dynamics simulations were performed on long tubes with free extremities, in order to lift the geometrical constraint imposed by the periodic boundary conditions. With this new procedure, some twisting of the nano-tube clearly appears (Figure 2 inset and Figure S5). This improved model is now compatible both with previous experimental data ${ }^{[8 c]}$ and with the present $C D$ results.

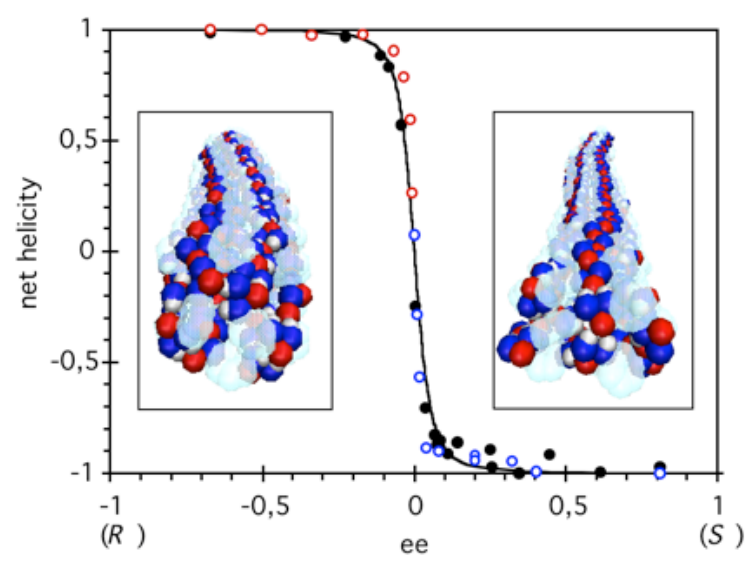

Figure 2. Net helicity $\left(\left(\Delta \varepsilon_{236}-\Delta \varepsilon_{224}\right) /\left(\Delta \varepsilon_{236}-\Delta \varepsilon_{224}\right) \max \right)$ versus enantiomeric excess (ee) of $1 \mathrm{mM}$ bis-urea solutions in cyclohexane at $20^{\circ} \mathrm{C}$, for the following mixtures: EHUT-SS / EHUT-RR (@); EHUT-SS / EHUT-rac (O); EHUT-RR / EHUT-rac (O).The curve is a fit of the EHUT-SS / EHUT-RR data. ${ }^{[13 c]}$ The ee is calculated as ([S]$[\mathrm{R}]) /([\mathrm{R}]+[\mathrm{S}])$, where $[\mathrm{R}]$ and $[\mathrm{S}]$ are the ethylhexyl concentrations, as deduced from the measured optical purity of the monomers. The insets show optimized geometries for an EHUT-RR (left) or EHUT-SS (right) nano-tube, determined by molecular mechanics and dynamics (see Figure S5 for details).

These results on chiral monomers encouraged us to investigate the effect of a chiral solvent. Limonene was selected because of (i) its size which is compatible with the inner space of the nanotubes $^{[8 \mathrm{~b}]}$, (ii) the absence of polar groups which would interfere with self-assembly by hydrogen bonding, and (iii) its commercial availability. FTIR and DSC experiments (Figures S6 and S7) confirm that the nano-tubes are formed in limonene, with a tube-tofilament transition temperature of $38^{\circ} \mathrm{C}$. Figure 3 shows the symmetrical CD spectra measured for EHUT-rac solutions in $(S)$ or $(R)$-limonene. The Cotton effects obtained for EHUT-rac in $(S)$ limonene and EHUT-SS in cyclohexane have nearly identical shapes: it indicates that the nano-tubes formed by the racemic monomer mixture in the chiral solvent and the chiral monomer in the achiral solvent have very similar structures. Moreover, the handedness of the helical assembly is the same whether it is induced by the $(S)$-limonene solvent or by the EHUT-SS monomer. Now, this raises the question of whether the chiral induction by the solvent is quantitative (like the chiral induction by the monomer) or only partial. The fact that the signal intensities in the CD spectra of Figure 3 are very similar does not necessarily mean that full chiral induction is achieved by chiral limonene, because the CD signal intensity is known to also depend on the solvent polarisability. ${ }^{[16]}$
To address this question, we performed the following experiment. Stock solutions of EHUT-rac in $(S)$ - or $(R)$-limonene were combined in different proportions and stirred at room temperature. The inset in Figure 3 shows the result of the CD measurements at equilibrium: the ellipticity is a linear function of the solvent enantiomeric excess. This points to a very different behavior (and energetics) when the helicity of the nano-tubes is biased through a chiral solvent or through a chiral monomer. However, we still do not know if full chiral induction is induced by the solvent, because no saturation of the helicity is reached. ${ }^{[13 \mathrm{c}]}$

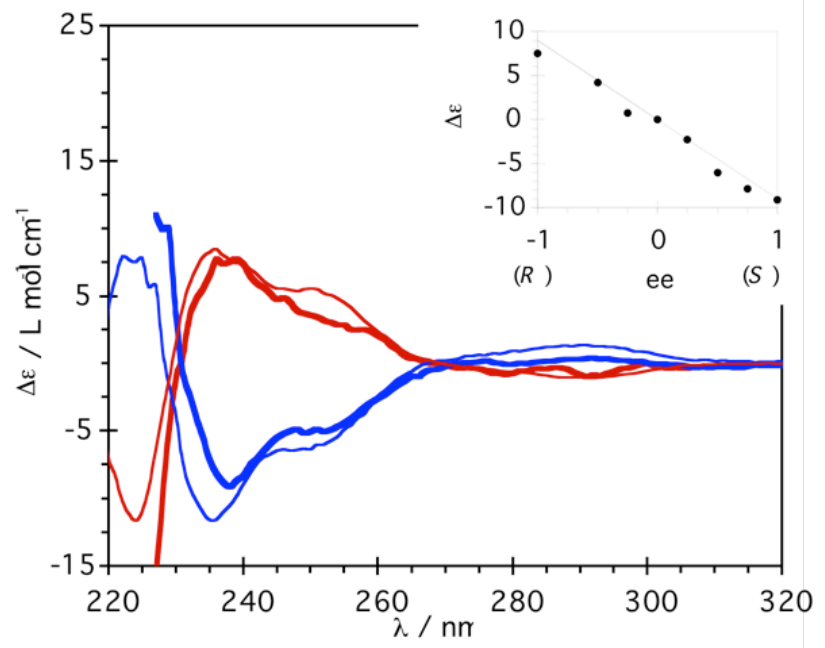

Figure 3. CD spectra at $20^{\circ} \mathrm{C}$ of bisurea solutions: EHUT-rac in $(S)$-limonene (-) or $(R)$-limonene (-) (10mM); EHUT-SS (-) or EHUT-RR (-) in cyclohexane (1mM). The inset shows the helicity measured at $238 \mathrm{~nm}$ versus the enantiomeric excess of EHUT-rac in $(S)$-limonene / $(R)$-limonene mixtures. ${ }^{[15]}$

Finally, the respective magnitude of the nano-tube helicity control by a chiral monomer or by a chiral solvent was probed through the following competition experiments. Figure 4 shows the results of the four possible combinations between the two chiral monomers and the two chiral solvents. Clearly, the handedness of the nano-tube is imposed by the monomer because the Cotton effect is of the same sign for EHUT-RR in both $(S)$ - and $(R)$-limonene. However, the intensity difference between these two spectra confirms the significant effect of the solvent. It is reasonable to assume that full chiral induction is reached for EHUT-RR in $(R)$ limonene, because this is already the case in cyclohexane (Figure 2). Therefore, the intensity of the Cotton effect for this system $(\Delta \varepsilon=$ $24.5 \mathrm{~L} \mathrm{~mol}^{-1} \mathrm{~cm}^{-1}$, Figure 4$)^{[17]}$ can be used to normalize the value obtained in the case of EHUT-rac in $(R)$-limonene $\left(\Delta \varepsilon=8.3 \mathrm{~L} \mathrm{~mol}^{-}\right.$ ${ }^{1} \mathrm{~cm}^{-1}$, Figure 3): this yields a value of $33 \%$ for the chiral induction by the chiral solvent. Although full chirality induction by the solvent alone is not reached, this value is quite significant.

Moreover, this value can now be used to determine the energetic parameters relevant for this chiral induction by the solvent. Although the theoretical model devised by van Gestel et al. was formally written for the case of a mixture of chiral monomers, it is equally valid for the present case of a one-dimensional assembly whose helicity is controlled by a chiral solvent. The lack of cooperativity of the experimental curve (Figure 3, inset) does not enable to determine both parameters $\varepsilon_{\text {reversal }}$ and $\varepsilon_{\text {mismatch }}$ 
independently. However, we can assume that the helix reversal penalty depends mainly on the hydrogen bonding pattern of the nano-tube and therefore not much on the solvent. If the previously determined minimum value of $\varepsilon_{\text {reversal }}$ is used $(17 \mathrm{~kJ} / \mathrm{mol})$, then a value $\varepsilon_{\text {mismatch }}=1.5 \mathrm{~J} / \mathrm{mol}(=0.0006 \mathrm{kT})$ affords a good fit of the data (Figure S8). Although this value is quite low, it is not unrealistic. Even lower values have been found in the case of chiral solvation for helical polymers. ${ }^{[2]}$

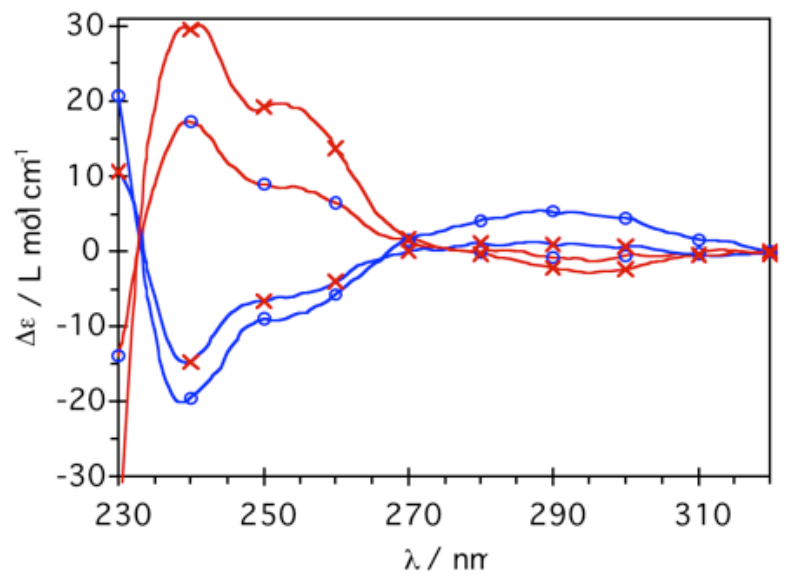

Figure 4. CD spectra at $20^{\circ} \mathrm{C}$ of $10 \mathrm{mM}$ bisurea solutions: EHUT-SS in $(S)$-limonene (o-); EHUT-SS in $(R)$-limonene (-x-); EHUT-RR in $(R)$-limonene $(-\mathrm{x}-)$; EHUT-RR in (S)-limonene (-o-).

\section{Conclusion}

In conclusion, we have shown for the first time that chiral dynamic self-assembled nano-tubes can be obtained from a racemic monomer in a chiral solvent. The helical bias induced by the particular solvent tested (limonene) is not as strong as the helical bias induced by a chiral monomer, but is still very significant (about 33\%). These results do not allow to determine if the solvent control on the nanotube helicity is effected by the limonene molecules present within the nano-tube or outside or both. However, it is tempting to assume that a host-guest type of interaction is operative, because it should be stronger than simple solvation. Finally, it is therefore not unreasonable to expect that a better chiral guest can be found which will induce a full helical bias of the nano-tubes.

\section{Acknowledgements}

We thank François Boué (LLB, Saclay) for assistance with SANS experiments.

[1] a) J. M. Fraile, J. I. Garcia, C. I. Herrerias, J. A. Mayoral, E. Pires, Chem. Soc Rev. 2009, 38, 695-706; b) R. Sancho, C. Minguillon, Chem. Soc. Rev. 2009, 38, 797-805.

[2] a) M. M. Green, J.-W. Park, T. Sato, A. Teramoto, S. Lifson, R. L. B. Selinger, J. V. Selinger, Angew. Chem. 1999, 111, 3328-3345; Angew. Chem. Int. Ed. 1999 38, 3138-3154; b) M. M. Green, K.-S. Cheon, S.-Y. Yang, J.-W. Park, S. Swansburg, W. Liu, Acc. Chem. Res. 2001, 34, 672-680.

[3] a) A. R. A. Palmans, E. W. Meijer, Angew. Chem. 2007, 119, 9106-9126; Angew. Chem. Int. Ed. 2007, 46, 8948-8968; b) S. Vazquez-Campos, M. CregoCalama, D. N. Reinhoudt, Supramol. Chem. 2007, 19, 95-106; c) M. M. J. Smulders, A. P. H. J. Schenning, E. W. Meijer, J. Am. Chem. Soc. 2008, 130, 606-611; d) A. Lohr, F. Würthner, Chem. Commun. 2008, 2227-2229; e) A. Lohr, F. Würthner, Angew. Chem. 2008, 120, 1252-1256; Angew. Chem. Int. Ed. 2008, 47, 1232-1236; f) T. Yamamoto, T. Fukushima, A. Kosaka, W. Jin, Y.
Yamamoto, N. Ishii; T. Aida, Angew. Chem. 2008, 120, 1696-1699; Angew. Chem. Int. Ed. 2008, 47, 1672-1675; g) T. Shikata, Y. Kuruma, A. Sakamoto, K Hanabusa, J. Phys. Chem. B 2008, 112, 16393-16402; h) T. E. Kaiser, V. Stepanenko, F. Würthner, J. Am. Chem. Soc. 2009, 131, 6719-6732.

[4] a) H. Fenniri, B-L. Deng, A. E. Ribbe, J. Am. Chem. Soc. 2002, 124, 11064 11072 ; b) H. von Berlepsch, S. Kirstein, C. Böttcher, J. Phys. Chem. B 2003 $107,9646-9654$; c) S. J. George, Z. Tomovic, M. M. J. Smulders, T. F. A. de Greef, P. E. L. G. Leclère, E. W. Meijer, A. P. H. J. Schenning, Angew. Chem. 2007, 119, 8354-8359; Angew. Chem. Int. Ed. 2007, 46, 8206-8211; d) J. Xiao, J. Xu, S. Cui, H. Liu, S. Wang, Y. Li Org. Lett. 2008, 10, 645-648; e) W. Cai, G.T. Wang, P. Du, R.-X. Wang, X.-K. Jiang, Z.-T. Li, J. Am. Chem. Soc. 2008 130, 13450-13459; f) V. Percec, M. R. Imam, M. Peterca, D. A. Wilson, R. Graf, H. W. Spiess, V. S. K. Balagurusamy, P. A. Heiney, J. Am. Chem. Soc. 2009, 131, 7662-7677; g) L. Zeng, Y. He, Z. Dai, J. Wang, Q. Cao, Y. Zhang, Chem. Phys. Chem. 2009, 10, 954-962.

[5] a) A. R. A. Palmans, J. A. J. M. Vekemans, E. E. Havinga, E. W. Meijer, Angew Chem. 1997, 109, 2763-2765; Angew. Chem. Int. Ed. 1997, 36, 2648-2651; b) L. Brunsveld, B. G. G. Lohmeijer, J. A. J. M. Vekemans, E. W. Meijer, J. Inclusion Phenom. Macrocyclic Chem. 2001, 41, 61-64; c) T. Ishi-i, T. Hirayama, K.-I. Murakami, H. Tashiro, T. Thiemann, K. Kubo, A. Mori, S. Yamasaki, T. Akao, A. Tsuboyama, T. Mukaide, K. Ueno, S. Mataka, Langmuir 2005, 21, 12611268; d) S. Ghosh, X.-Q. Li, V. Stepanenko, F. Würthner, Chem. Eur. J. 2008, $14,11343-11357$

[6] For achiral solvent effects, see: a) R. S. Johnson, T. Yamazaki, A. Kovalenko, H. Fenniri, J. Am. Chem. Soc. 2007, 129, 5735-5743; b) K. Jyothish, M. Hariharan, D. Ramaiah, Chem. Eur. J. 2007, 13, 5944-5951.

[7] For chiral solvation effects in related systems, see: a) C. A. Khatri, Y. Pavlova, M. M. Green, H. Morawetz, J. Am. Chem. Soc. 1997, 119, 6991-6995; b) R. B. Prince, S. A. Barnes, J. S. Moore, J. Am. Chem. Soc. 2000, 122, 2758-2762; c) P. Dellaportas, R. G. Jones, S. J. Holder, Macromol. Rapid Commun. 2002, 23, 99103.

[8] a) L. Bouteiller, O. Colombani, F. Lortie, P. Terech, J. Am. Chem. Soc. 2005 , 127, 8893-8898; b) T. Pinault, B. Isare, L. Bouteiller, Chem. Phys. Chem. 2006, 7, 816-819; c) T. Shikata, T. Nishida, B. Isare, M. Linares, R. Lazzaroni, L. Bouteiller, J. Phys. Chem. B 2008, 112, 8459-8465; d) M. Bellot, L. Bouteiller, Langmuir 2008, 24, 14176-14182; e) B. Isare, M. Linares, R. Lazzaroni, L. Bouteiller, J. Phys. Chem. B 2009, 113, 3360-3364.

[9] a) H. Fenniri, P. Mathivanan, K. L. Vidale, D. M. Sherman, K. Hallenga, K. V. Wood, J. G. Stowell, J. Am. Chem. Soc. 2001, 123, 3854-3855; b) J. G. Moralez, J. Raez, T. Yamazaki, R. K. Motkuri, A. Kovalenko, H. Fenniri, J. Am. Chem. Soc. 2005, 127, 8307-8309; c) S. Stoncius, E. Orentas, E. Butkus, L. Ohrstrom, O. F. Wendt, K. Warnmark, J. Am. Chem. Soc. 2006, 128, 8272-8285; d) G. D. Pantos, P. Pengo, J. K. M. Sanders, Angew. Chem. 2007, 119, 198-201; Angew. Chem. Int. Ed. 2007, 46, 194-197; e) G. D. Pantos, J.-L. Wietor, J. K. M. Sanders, Angew. Chem. 2007, 119, 2288-2290; Angew. Chem. Int. Ed. 2007, 46 , 2238-2240.

[10] M. Miura, M. Toriyama, S. Motohashi, Synth. Commun. 2006, 36, 259-264.

[11] a) Y. Ishida, T. Aida, J. Am. Chem. Soc. 2002, 124, 14017-14019; b) A. Brizard, R. Oda, I. Huc, Top. Curr. Chem. 2005, 256, 167-218; c) J. Seo, J. W. Chung, E.-H. Jo, S. Y. Park, Chem. Commun. 2008, 2794-2796.

[12] These experiments were characterized by a strong time-dependence: approximately 10 hours were needed before the CD effect was fully developed after mixing solutions of the enantiomers.

[13] a) J. van Gestel, P. van der Schoot, M. A. J. Michels, Macromolecules 2003, 36 6668-6673; b) J. van Gestel, P. van der Schoot, M. A. J. Michels, J. Chem. Phys. 2004, 120, 8253-8261; c) J. van Gestel, Macromolecules 2004, 37, 3894-3898; d) J. van Gestel, A. R. A. Palmans, B. Titulaer, J. A. J. M. Vekemans, E. W. Meijer, J. Am. Chem. Soc. 2005, 127, 5490-5494; e) J. van Gestel, J. Phys. Chem. B 2006, 110, 4365-4370.

[14] M. Linares, A. Minoia, P. Brocorens, D. Beljonne, R. Lazzaroni, Chem. Soc Rev. 2009, 38, 806-816.

[15] Because the UV absorption of limonene is higher than that of cyclohexane, the pathlength of the cell for CD measurement had to be reduced, and consequently, the bis-urea concentration had to be increased in limonene (see Supporting Information)

[16] Biophysical chemistry, Part II (Ed.: C. R. Cantor, P. R. Schimmel), W. H. Freeman \& Co, New York, 1998.

[17] This value is the average between EHUT-RR and EHUT-SS data. The difference between both data is due to the difficulty to precisely control the pathlength of the very thin cell $(0.001 \mathrm{~cm})$. 
